\title{
Peripheral polyneuropathy and monoclonal gammopathy of undetermined significance
}

\author{
MJ KROL-V STRAATEN, ${ }^{*}$ RGA ACKERSTAFF, $\dagger$ CEM DE MAAT* \\ From the Departments of Internal Medicine* and Clinical Neurophysiology, $†$ St Antonius Ziekenhuis, The \\ Netherlands
}

SUMMARY The prevalence of peripheral polyneuropathy in patients with monoclonal gammopathy is known to be higher than in the general population. A prevalence as high as that in the series of Osby et al, who found clinical and/or electrophysiological evidence compatible with peripheral polyneuropathy in 15 of 21 patients has not been reported before. These results could not be confirmed in a study in which 19 patients with benign monoclonal gammopathy were investigated. In contrast there were only two patients with questionable evidence of peripheral neuropathy: one had lower limb symptoms and signs only, the other had evidence of a subclinical polyneuropathy with some abnormalities of nerve conduction.

We were surprised by the high incidence of peripheral polyneuropathy found in patients with benign monoclonal gammopathy in the series of Osby et al. ${ }^{1}$ We therefore examined 19 similar patients for the presence of peripheral polyneuropathy.

\section{Patients and methods}

Unselected consecutive patients who were known to have a monoclonal gammopathy, were asked to take part in the study. Patients were excluded if they were known or suspected to be suffering from another disease that might be associated with peripheral polyneuropathy. One patient (No 14) had a biclonal paraproteinaemia. All patients underwent thorough neurological and haematological evaluation, including serum and urine immunoelectrophoresis with typing of heavy and light chains, bone marrow aspirations and biopsies, and skeletal radiography. At the time of the study all patients were considered to have benign paraproteinaemia (however, one patient, No 9 , admitted because of radiographic chest abnormalities thought to be caused by fungal infection and who was considered to have benign paraproteinaemia, proved to be suffering from pulmonary amyloidosis at necropsy six

Address for reprint requests: Dr MJ Krol-v Straaten, St Antonius Hospital, Koekoekslaan 1, 3435 CM Nieuwegein, The Netherlands.

Received 5 September 1984 and in revised form 9 November 1984. Accepted 17 November 1984 months later. Bone marrow examination after death was compatible with multiple myeloma, in contrast to the examination during life).

Electromyographic and electroneurographic studies were performed in a warm, dry room with the patient supine. Needle electromyography was performed with concentric needle electrodes. Spontaneous activity (fibrillations and positive sharp waves and motor unit action potentials) were analysed subjectively. In all patients maximal motor and sensory nerve conduction velocities were measured orthodromically in the median nerve. In one patient (No 19) the same was done in the tibial nerve. The nerves were stimulated with needle electrodes. ${ }^{2}$ The compound muscle action potential was recorded with surface electrodes. Sensory nerve action potentials were recorded with needle electrodes at wrist and elbow after stimulation of the digital nerves of the thumb. All responses were photographed for subsequent analysis. Conduction velocities and distal motor latencies were determined in conventional fashion. The values were corrected for the influence of temperature, measured near the nerve at the site of stimulation with a needle electrode. The findings were compared to age-equilibrated normal values ${ }^{3}$ and differences of the mean value minus two standard deviations were judged to be pathological. The amplitude of the sensory nerve action potential was measured from peak to peak.

\section{Results}

The results of the clinical, haematological and neurophysiological examinations are summarised in 
Table

\begin{tabular}{|c|c|c|c|c|c|c|c|c|c|c|c|}
\hline \multicolumn{4}{|c|}{ Patient characteristics } & \multirow{3}{*}{$\begin{array}{l}\text { Clinical } \\
\text { polyneuropathy }\end{array}$} & \multicolumn{4}{|c|}{ Monoclonal protein } & \multicolumn{3}{|c|}{ Electrophysiological investigation } \\
\hline \multirow[t]{2}{*}{ Patient } & \multirow[t]{2}{*}{ Sex } & \multirow{2}{*}{$\begin{array}{l}\text { Age at } \\
\text { diagnosis } \\
(y r)\end{array}$} & \multirow{2}{*}{$\begin{array}{l}M G \\
\text { duration } \\
\text { mg (month) }\end{array}$} & & \multirow{2}{*}{$\begin{array}{l}\text { Heavy } \\
\text { chain }\end{array}$} & \multirow{2}{*}{$\begin{array}{l}\text { Light } \\
\text { chain }\end{array}$} & \multirow{2}{*}{$\begin{array}{l}\text { Quantity } \\
\text { diagnosis }\end{array}$} & \multirow{2}{*}{$\begin{array}{l}(g / l) \\
\text { study }\end{array}$} & \multirow{2}{*}{$\begin{array}{l}\text { At motor } \\
C V / D L\end{array}$} & \multicolumn{2}{|l|}{ Sensory } \\
\hline & & & & & & & & & & $D C V / A m p$ & $P C V / A m p$ \\
\hline $\begin{array}{r}1 \\
2 \\
3 \\
4 \\
5 \\
6 \\
7 \\
8 \\
9 \\
10 \\
11 \\
-12 \\
13\end{array}$ & 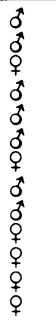 & $\begin{array}{l}57 \\
59 \\
53 \\
59 \\
56 \\
58 \\
26 \\
69 \\
77 \\
50 \\
70 \\
72 \\
73\end{array}$ & $\begin{array}{r}18 \\
54 \\
16 \\
42 \\
18 \\
54 \\
30 \\
1 \\
6 \\
5 \\
90 \\
42 \\
44\end{array}$ & $\begin{array}{l}- \\
- \\
- \\
- \\
- \\
- \\
- \\
-\end{array}$ & $\begin{array}{l}\mathbf{A} \\
\mathbf{G} \\
\mathbf{G} \\
\mathbf{G} \\
\mathbf{G} \\
\mathbf{G} \\
\mathbf{A} \\
\mathbf{G} \\
\mathbf{G} \\
\mathbf{G} \\
\mathbf{G} \\
\mathbf{M}\end{array}$ & $\begin{array}{l}\lambda \\
\lambda \dagger \\
\lambda \\
\lambda \\
\mathbf{K} \\
\mathbf{K} \\
\mathbf{K} \\
\mathbf{K} \\
\mathbf{K} \\
\mathbf{K} \\
\mathbf{K} \\
\lambda \\
\mathbf{K}\end{array}$ & $\begin{array}{l}9 \\
0 \cdot 05+ \\
13 \\
6 \\
5 \\
18 \\
24 \\
22 \\
20 \\
14 \\
10 \\
10 \\
10\end{array}$ & $\begin{array}{r}10 \\
1 \\
11 \\
8 \\
7 \\
21 \\
29 \\
22 \\
20 \\
14 \\
9 \\
19 \\
15\end{array}$ & $\begin{array}{l}51 / 3 \cdot 6 \\
56 / 4 \cdot 5 \\
53 \cdot 5 \cdot 6 \\
54 / 6 \cdot 0 \\
67 / 4 \cdot 1 \\
58 / 3 \cdot 2 \\
59 / 3 \cdot 7 \\
53 / 4 \cdot 4 \\
51 / 3 \cdot 8 \\
56 / 3 \cdot 6 \\
52 / 4 \cdot 2 \\
49 / 3 \cdot 5 \\
48 / 6 \cdot 7\end{array}$ & $\begin{array}{l}46 / 20 \\
44 / 30 \\
25 / 7 \\
30 / 9 \\
47 / 22 \\
40 / 18 \\
40 / 25 \\
36 / 24 \\
46 / 20 \\
53 / 36 \\
40 / 26 \\
44 / 7 \\
37 / 3\end{array}$ & $\begin{array}{l}52 / 5 \\
59 / 6 \\
64 / 8 \\
58 / 4 \\
63 / 5 \\
61 / 16 \\
64 / 8 \\
60 / 5 \\
58 / 1 \\
65 / 15 \\
59 / 5 \\
54 / 3 \\
57 / 3\end{array}$ \\
\hline-14 & $a$ & 65 & 144 & - & & $\mathbf{K}$ & 8 & 16 & $49 / 4 \cdot 0$ & $30 / 14$ & $58 / 3$ \\
\hline $\begin{array}{l}15 \\
16 \\
17 \\
18 \\
19\end{array}$ & 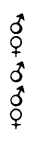 & $\begin{array}{l}70 \\
57 \\
65 \\
55 \\
73\end{array}$ & $\begin{array}{l}18 \\
42 \\
22 \\
36 \\
54\end{array}$ & $\begin{array}{l}- \\
- \\
\overline{\text { polyneuropathy }} \\
\text { legs }\end{array}$ & $\begin{array}{l}\mathbf{G} \\
\mathbf{G} \\
\mathbf{M} \\
\mathbf{G} \\
\mathbf{G}\end{array}$ & $\begin{array}{l}\mathbf{K} \\
\mathbf{K} \\
\mathbf{K} \\
\lambda \\
\mathbf{K}\end{array}$ & $\begin{array}{l}5 \\
11 \\
8 \\
11 \\
\text { unknown }\end{array}$ & $\begin{array}{r}6 \\
8 \\
6 \\
11 \\
13\end{array}$ & $\begin{array}{l}53 / 3 \cdot 9 \\
50 / 4 \cdot 5 \\
53 / 4 \cdot 3 \\
53 / 3 \cdot 9 \\
55 / 4 \cdot 4 \\
38 / 4 \cdot 2 \ddagger\end{array}$ & $\begin{array}{l}45 / 14 \\
45 / 8 \\
40 / 15 \\
39 / 30 \\
35 / 22 \\
27 / 0.6 \ddagger\end{array}$ & $\begin{array}{l}59 / 4 \\
56 / 5 \\
63 / 2 \\
61 / 6 \\
63 / 3 \\
35 / 0+\end{array}$ \\
\hline
\end{tabular}

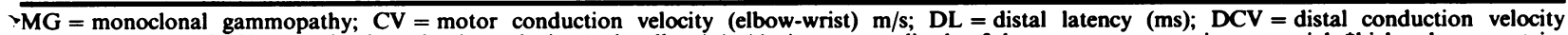

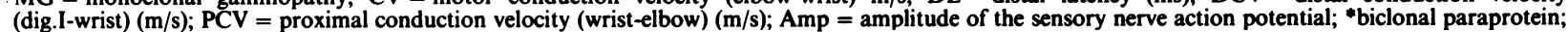
+Bence Jones proteinuria only, concentration in urine; $¥$ Investigation of the $\mathbf{N}_{0}$ tibialis posterior; PCV $=$ ankle-knee conduction velocity.

the table. In none of the patients did the electromyographic examination yield signs of axonal degeneration. Fibrillations and positive sharp waves were not found in any of the muscles investigated and muscle action potentials were normal related to the age of the patients. Only one of our patients (No 19) with IgG paraproteinaemia had clinically distinctive symptoms and signs of polyneuropathy of the legs, consisting of paraesthesia and impairment of sensation in the feet and the lower legs; knee and ankle tendon jerks were absent. In this patient nerve conduction velocity measurements were normal in the arms but abnormal in the legs. In the other 18 patients there was no clinical evidence of a polyneuropathy. In one patient with IgG monoclonal immunoglobulin (No 3) distal motor latency was delayed and maximal sensory nerve conduction velocity through the carpal tunnel was decreased. A second neurological examination of this patient revealed questionable signs of a carpal tunnel syndrome. In another patient with IgM monoclonal immunoglobulin (No 13) only the distal motor latency was delayed and this patient showed no evidence of a carpal tunnel syndrome. All other nerve conduction velocity measurements revealed normal values related to the age of the patients.

\section{Discussion}

Peripheral polyneuropathy associated with monoclonal gammopathy is currently receiving a consid- erable amount of attention in the literature..$^{14-7} \mathrm{We}$ could not confirm the high prevalence of peripheral polyneuropathy in patients with benign monoclonal gammopathy found in the series of Osby et al, ${ }^{1}$ either clinically or electrophysiologically. One of our two patients with IgM paraproteinaemia (No 13) had discrete electrophysiological abnormalities (delayed distal motor latency). In only one of our 16 patients with IgG or IgA paraproteinaemia was there evidence of peripheral polyneuropathy. However, she had lesions in the lower limbs only, which is difficult to attribute to a paraprotein which must circulate throughout the body. Concerning the neurophysiological examination it should be noted that the methods of investigation were not identical. We think it improbable, however, that this would account for the wide difference between the results of the studies. Our electrophysiological results are in concordance with our clinical examination. Furthermore the abnormalities at electrophysiological examination as reported in the literature ${ }^{58}$ are obvious: conduction velocities are markedly decreased and often evidence is found for axonal degeneration. Such abnormalities would not be obscured by a different method of investigation. Unfortunately the article of Osby et al $^{1}$ does not give the figures of the measured conduction velocities and latencies.

Several comments can be made on our series, notably the inclusion of one patient with Bence Jones proteinuria (No 2) and one patient who later proved 
to have amyloidosis at necropsy (No 9). If anything this would have biased our results towards an increased prevalence of peripheral polyneuropathy. The prevalence reported in our study is comparable to that reported in the literature. However, from such a small series no general conclusion can be drawn about the frequency of polyneuropathy in patients with paraproteinaemia.

\section{References}

' Osby E, Noring L, Hast R, Kjellin KG, Knutson E, Sidén $\AA$. Benign monoclonal gammopathy and peripheral neuropathy. Br J Haematol 1982;51:5319.

${ }^{2}$ Buchthal F, Rosenfalck A. Evoked action potentials and conduction velocity in human peripheral nerves. Brain Res 1966;3:1-119.

${ }^{3}$ Buchthal F, Rosenfalck A, Behse F. Sensory potentials of normal and diseased nerves. In: Dyck PJ, Thomas PK, Lambert EH, eds. Peripheral Neuropathy. London: WB Saunders, 1975:442-64.

${ }^{4}$ Kahn SN, Riches PG, Kohn J. Paraproteinaemia in neurological disease: incidence, associations and classifications of monoclonal immunoglobulins. $J$ Clin Pathol 1980;33:617-21.

${ }^{5}$ Kelly JJ. The electrodiagnostic findings in peripheral neuropathy associated with monoclonal gammopathy. Muscle Nerve 1983;6:504-9.

${ }^{6}$ Mähönen M, Partanen J, Collan Y, Naukkarinen A, Sorvari T, Sivenios J, Riekkinen P. Monoclonal gammopathy with neurological and muscle biopsy study. Acta Neurol Scand 1982;66:643-51.

' Smith IS, Kahn SN, Lacey BW, et al. Chronic demyelinating neuropathy associated with benign IgM paraproteinaemia. Brain 1983;106:169-95.

${ }^{8}$ Dalakas MC, Engel WK. Polyneuropathy with monoclonal gammopathy: studies of 11 patients. Ann Neurol 1981;10:45-52. 